\title{
Acute Organophosphate Poisoning in University Hospital Emergency Room Patients
}

\author{
Yusuf Yurumez ${ }^{1}$, Polat Durukan ${ }^{2}$, Yucel Yavuz ${ }^{1}$, Ibrahim Ikizceli², Levent Avsarogullari², \\ Seda Ozkan ${ }^{2}$, Okhan Akdur ${ }^{2}$ and Caglar Ozdemir ${ }^{3}$
}

\begin{abstract}
Objects In the present study, we evaluated patients who were admitted to our emergency department with a diagnosis of organophosphate poisoning and discussed clinical, social and demographic features.

Methods A retrospective study was conducted with organophosphate poisoning patients admitted to our emergency department between January 1995 and December 2004. Data regarding the age, sex, occupation, type of agent, route of poisoning, clinical effects of cholinergic overactivity, laboratory findings, and mortality rate were obtained from the patient files.

Results During the study period, 220 patients who had organophosphate poisoning with a known agent were admitted to the ED. The estimated mean admission time to the ED after the exposure was $3.9 \pm 3.1$ (114) hours. There were $131(59.5 \%)$ female and 89 (40.5\%) male patients. The most affected age group was $15-24$ years $(40.5 \%)$, in both sexes. Oral ingestion $(86.5 \%)$ was found to be the most common route of poisoning. The most frequent reason for poisoning was attempted suicide $(75.9 \%)$. The most common organophosphate compounds exposed were dichlorvos, diazinon and parathion-methyl. The most frequent clinical signs were miosis, respiratory system findings, tachycardia, loss of consciousness, and hypertension. Twenty patients $(9.1 \%)$ died due to sudden respiratory and cardiac arrest $(45 \%)$, respiratory failure $(25 \%)$, CNS depression (5\%) and septic shock (25\%).

Conclusion We think that the appropriate use of these compounds, instruction of the public about their harmful effects and restriction of their uncontrolled sales by legal regulations can reduce the incidence of organophosphate poisoning.
\end{abstract}

Key words: organophosphates, poisoning, medicine, emergency

(DOI: 10.2169/internalmedicine.46.6304)

\section{Introduction}

Organophosphate compounds (OPCs), used commonly in agriculture, are a gradually increasing cause of accidental and suicidal poisoning, with high morbidity and mortality rates, especially in developing countries. OPCs may be taken via the oral, respiratory, or transdermal routes $(1,2)$. Globally, poisoning due to OPCs is responsible for approximately 3 million episodes, which result in nearly 200,000 deaths every year (3).

The mechanism of action of OPCs is related to inhibition of acetylcholine esterase (AChE), and inhibition of this en- zyme leads to accumulation of acetylcholine at nerve synapses and neuromuscular junctions, resulting in overstimulation of acetylcholine receptors. The initial overstimulation is followed by paralysis of cholinergic synaptic transmission in the central nervous system (CNS), in autonomic ganglia, at parasympathetic and some sympathetic nerve endings (e.g., sweat glands), and in somatic nerves $(4,5)$.

Signs of organophosphate poisoning (OPP) may be classified into effects secondary to muscarinic, nicotinic, and central nervous system receptor overstimulation. Muscarinic overstimulation is manifested as hyperactivity of the parasympathetic system, including miosis, bradycardia, and bronchial glands. Nicotinic effects include muscle fascicula-

\footnotetext{
${ }^{1}$ Department of Emergency Medicine, Kocatepe University Medical Faculty, Afyonkarahisar, Turkiye, ${ }^{2}$ Department of Emergency Medicine, Erciyes University Medical Faculty, Kayseri, Turkiye and ${ }^{3}$ Department of Forensic Medicine, Kayseri, Erciyes University Medical Faculty, Turkiye Received for publication October 11, 2006; Accepted for publication January 17, 2007
} Correspondence to Dr. Ibrahim Ikizceli, ikizceli@erciyes.edu.tr 
Table 1. Distribution of Patients According to Age and Sex

\begin{tabular}{lcccccc}
\hline Age groups & \multicolumn{2}{c}{ Male } & \multicolumn{2}{c}{ Female } & \multicolumn{2}{c}{ Total } \\
& $\mathbf{n}$ & $\%$ & $\mathbf{n}$ & $\%$ & $\mathbf{n}$ & $\%$ \\
\hline \hline $15-24$ & 29 & 13.2 & 60 & 27.3 & 89 & 40.5 \\
$25-34$ & 17 & 7.7 & 32 & 14.5 & 49 & 22.3 \\
$35-44$ & 16 & 7.3 & 16 & 7.3 & 32 & 14.5 \\
$55-64$ & 11 & 5 & 10 & 4.5 & 21 & 9.5 \\
$65-74$ & 10 & 4.5 & 5 & 2.3 & 15 & 6.8 \\
$>75$ & 6 & 2.7 & 8 & 3.6 & 14 & 6.4 \\
\hline Total & $\mathbf{8 9}$ & $\mathbf{4 0 . 4}$ & $\mathbf{1 3 1}$ & $\mathbf{5 9 . 6}$ & $\mathbf{2 2 0}$ & $\mathbf{1 0 0}$ \\
\hline
\end{tabular}

tion, cramping, and weakness while respiratory depression, seizures, and unconsciousness are the consequence of central nervous system effects (6).

As poisoning with OPCs is seen in many countries and sometimes causes mass poisoning $(7,8)$, it is also one of the most common causes of poisoning in Turkey (9). In the present study, we evaluated 220 patients who were admitted to our emergency department (ED) with diagnosis of OPP and discussed clinical, social and demographic features.

\section{Patients and Methods}

A retrospective study was conducted on patients with OPP admitted to our ED between January 1995 and December 2004. Two hundred twenty patients were included in the study. Patients were assessed at the time of admission. A detailed history had been taken from the patient or patient's family.

The diagnosis of acute OPP was based on the following criteria: 1) history of exposure to or contact with insecticide; 2) characteristic clinical signs and symptoms of OPP; 3) improvement of signs and symptoms with atropine and oximes, and 4) decreased serum cholinesterase (sChE) activity.

Biochemical parameters, complete blood count, serum amylase, sChE level, and troponin levels were measured with Konelab 60I autoanalyzer (Thermo Clinical Labsystem, Vantaa, Finland), after clinical assessment.

Admissions were always through the ED where initial decontamination procedures were carried out. These included skin decontamination by removal of all clothing, washing skin and hair with soap and water, and gastrointestinal decontamination by gastric lavage, cathartics and activated charcoal. All cases were treated with repeated doses of intravenous atropine and some patients were treated with oximes. Data regarding the age, sex, occupation, type of agent, route of poisoning, clinical effects of cholinergic overactivity, laboratory findings, and mortality rate were obtained from the patient files. These were recorded using standardized data collection forms and were analyzed with SPSS soft-
Table 2. The Route of Poisoning According to Age

\begin{tabular}{lcccccccccc}
\hline & Inhalation & \multicolumn{2}{l}{ Skin } & Ingestion & Intravenous & \multicolumn{2}{c}{ Total } \\
Age & & & & & & & & & & \\
groups & $\mathbf{n}$ & $\%$ & $\mathbf{n}$ & $\%$ & $\mathbf{n}$ & $\%$ & $\mathbf{n}$ & $\%$ & $\mathbf{n}$ & $\%$ \\
\hline \hline $15-24$ & 5 & 2.3 & 2 & 0.9 & 80 & 36.3 & 2 & 0.9 & 89 & 40.4 \\
$25-34$ & 3 & 1.4 & 3 & 1.4 & 43 & 19.4 & & & 49 & 22.2 \\
$35-44$ & 3 & 1.4 & 1 & 0.5 & 28 & 12.7 & & & 32 & 14.6 \\
$55-64$ & 3 & 1.4 & & & 18 & 8.2 & & & 21 & 9.6 \\
$65-74$ & 3 & 1.4 & & & 12 & 5.4 & & & 15 & 6.8 \\
$>75$ & 3 & 1.4 & 1 & 0.5 & 10 & 4.5 & & & 14 & 6.4 \\
\hline Total & $\mathbf{2 0}$ & $\mathbf{9 . 3}$ & $\mathbf{7}$ & $\mathbf{3 . 3}$ & $\mathbf{1 9 1}$ & $\mathbf{8 6 . 5}$ & $\mathbf{2}$ & $\mathbf{0 . 9}$ & $\mathbf{2 2 0}$ & $\mathbf{1 0 0}$ \\
\hline
\end{tabular}

ware.

\section{Results}

During the study period, 220 patients who had OPP with a known agent were admitted to the ED. In this period of time approximately 305,000 patients were admitted to the ED. The estimated mean admission time to the ED after the exposure was $3.9 \pm 3.1$ hours (Min: 1, Max: 14 hours: $4 \pm$ 1.9 hours in dead cases and $3.9 \pm 3.2$ hours in discharged patients).

Table 1 presents the distribution of patients according to age and sex. There were $131(59.5 \%)$ female and 89 (40.5\%) male patients and the female/male ratio was 1.47 . The most frequently affected age group was $15-24$ years in both sexes $(40.5 \%)$ and in discharged patients $(42 \%)$, but it was 15-24 years and above 75 years in dead cases $(25 \%$ each). One hundred forty-one $(67.3 \%)$ of the patients were married and the majority of them were housewives (47.3\%). Residency distribution patterns showed that $44.5 \%$ of the patients came from rural areas, while $55.5 \%$ were from urban areas

Routes of intake were inhalation, transdermal, oral ingestion, and intravenous injection. Oral ingestion (86.5\%) was found to be the most common route of poisoning (19 of dead cases and 172 of discharged patients) (Table 2). A total of $45(20.5 \%)$ patients were exposed to the agent accidentally and 8 patients $(3.6 \%)$ had occupational exposure. But, the most frequent reason for poisoning was attempted suicide $(75.9 \%$ ) (Table 3). The suicide attempt rate was $75 \%$ in dead cases and $76 \%$ in discharged patients. The most common OPCs exposed were dichlorvos, diazinon and parathion-methyl. The average volume of exposed OPCs was $48.9 \pm 52.5 \mathrm{~mL}$ (Min: $1 \mathrm{~mL}$, Max: $500 \mathrm{~mL}$; $69 \pm 33$ $\mathrm{mL}$ in dead cases and $47 \pm 53 \mathrm{~mL}$ in discharged patients).

The clinical findings on admission are summarized in Table 4 . The most frequent clinical signs were miosis, respiratory system findings, tachycardia, loss of consciousness, and hypertension. There was an increase in serum liver enzymes, lactate dehydrogenase, glucose, amylase and troponin levels, 
Table 3. The Route of Poisoning According to Reason

\begin{tabular}{lcccccccccc}
\hline & \multicolumn{2}{c}{ Inhalation } & \multicolumn{2}{c}{ Skin } & \multicolumn{2}{c}{ Ingestion } & \multicolumn{2}{c}{ Intravenous } & \multicolumn{2}{c}{ Total } \\
Reason & $\mathbf{n}$ & $\mathbf{\%}$ & $\mathbf{n}$ & $\mathbf{\%}$ & $\mathbf{n}$ & $\mathbf{\%}$ & $\mathbf{n}$ & $\mathbf{\%}$ & $\mathbf{n}$ & $\mathbf{\%}$ \\
\hline \hline Suicidal & 1 & 0.5 & & & 164 & 74.5 & 2 & 0.9 & 167 & $\mathbf{7 5 . 9}$ \\
Accidental & 12 & 5.4 & $\mathbf{6}$ & 2.7 & 27 & 12.3 & & & 46 & 20.5 \\
Occupational & 7 & 3.2 & 1 & 0.5 & & & & & 8 & 3.6 \\
\hline Total & $\mathbf{2 0}$ & $\mathbf{9 . 1}$ & $\mathbf{7}$ & $\mathbf{3 . 2}$ & $\mathbf{1 9 1}$ & $\mathbf{8 6 . 8}$ & $\mathbf{2}$ & $\mathbf{0 . 9}$ & $\mathbf{2 2 0}$ & $\mathbf{1 0 0}$ \\
\hline
\end{tabular}

Table 4. Clinical Manifestations of Patients

\begin{tabular}{lcc}
\hline Clinical Manifestations & \multicolumn{2}{c}{ Affected patients } \\
& N & \% \\
\hline \hline Miosis & 175 & 74.5 \\
Respiratory tract findings & 120 & 54.6 \\
Tachycardia & 78 & 35.4 \\
Emesis & 72 & 32.7 \\
Loss of consciousness & 67 & 30.4 \\
Hyperhydrosis & 63 & 28.6 \\
Hypertension & 32 & 14.5 \\
Fasciculation & 18 & 8.2 \\
Bradycardia & 11 & 5 \\
Fever & 10 & 4.5 \\
Diarrhea or urinary & 4 & 1.8 \\
incontinence & & \\
Convulsion & 4.7 \\
Hypotension & & \\
\hline & & \\
\hline
\end{tabular}

and also leukocyte count (Table 5).

Twenty patients $(9.1 \%)$ died due to sudden respiratory and cardiac arrest (45\%), respiratory failure (25\%), septic shock (25\%) and CNS depression (5\%) (Table 6). Two hundred patients $(90.9 \%)$ were discharged with no symptoms.

\section{Discussion}

OPCs have largely been used as pesticides in many parts of the world (10). They are readily available because of inadequate regulations controlling their sale (11). This easy availability of the compounds has resulted in a gradual increase in accidental and suicidal poisoning (9).
Table 5. Abnormal Laboratory Findings of Patients

\begin{tabular}{|c|c|c|}
\hline Findings & Normal values & Patient values \\
\hline Leukocyte count & $4000-10000$ & $13.465 \pm 5.78$ \\
\hline Blood glucose (mg/dL) & $70-110$ & $145 \pm 68$ \\
\hline Lactate dehydrogenase (U/L) & $225-450$ & $458.2 \pm 377.8$ \\
\hline Aspartate aminotransferase (U/L) & $0-32$ & $37.5 \pm 72.1$ \\
\hline Amylase (U/L) & $28-100$ & $150.6 \pm 197.3$ \\
\hline Troponin I (U/L) & $<0.1$ & $1.3 \pm 0.2$ \\
\hline Serum AChE (U/L) Female & $5600-17600$ & $1592.6 \pm 1735$ \\
\hline Serum AChE (U/L) & $4000-12000$ & $1918.5 \pm 2155.4$ \\
\hline
\end{tabular}

Table 6. The Causes for Mortality of Patients

\begin{tabular}{lcc}
\hline & \multicolumn{2}{c}{ Affected patients } \\
& n & \% \\
\hline \hline Sudden respiratory & 9 & 45 \\
and cardiac arrest & & \\
Respiratory failure & 5 & 25 \\
Septic Shock & 5 & 25 \\
CNS depression & 1 & 5 \\
\hline Total & $\mathbf{2 0}$ & $\mathbf{1 0 0}$ \\
\hline
\end{tabular}

Poisoning with OPCs may occur at all ages $(7,8)$. The most commonly affected age group in our study was 15-24 years, with the female to male ratio being 1.47. From this aspect, the present results are in agreement with those of the literature (11-14).

In contrast to the findings of Saadeh et al (11) and Kara et al (14), in our study, there were more married patients $(67.3 \%)$ than unmarried $(31.8 \%)$. But, the marriage rate of our patients was similar to that of Agarwal et al, and Chharba et al $(15,16)$. This may be related to the sociocultural structure of the exposed population in our country.

Ingestion of OPCs in an attempt to commit suicide is a major problem especially for developing countries (9), and severe cases are mostly due to suicidal use (17-19). Accidental exposure is the main cause of mild poisoning (2022). OPP due to suicidal attempt accounts for at least 40$60 \%$ of all cases in some African countries (9). In the present study, the rate of suicidal poisoning was $75.9 \%$, and the major route of intake of OPCs was ingestion (86.8\%). These high ratios of suicidal poisoning and intake by oral means are similar to those of Sungur and Guven (9) and Saadeh et al (11). These high ratios may be due to uncontrolled sales 
and the wide use of these agents all over the country.

The type of OPCs as the agent of poisoning was noted to be varied in different studies. For instance, fenitrothion was reported by Yamashita et al, dichlorvos by Sungur and Guven and Saadeh et al, and mevinphos by Nouria et al as the most common causative agent $(6,9,11,23)$. We also found dichlorvos to be the most common OPC as the agent of poisoning. We think that this may be due to the fact that dichlorvos is one of the most commonly sold insecticides in Turkey.

The symptoms of OPP are related to subsequent accumulation of acetylcholine, which is usually termed cholinergic crisis. The signs of OPP may be classified as effects secondary to muscarinic, nicotinic, and central nervous system receptor overstimulation (6). Clinical presentation depends on the specific agent involved, the quantity absorbed, and the type of exposure (4). The most frequent sign in OPP is miosis (12). Miosis was also the most significant sign in the present patient $(74.5 \%)$. This finding is similar in several studies $(11,12)$. Other frequent signs were respiratory system findings, tachycardia, emesis, loss of consciousness, hyperhydrosis, hypertension, fasciculation, bradycardia, fever, diarrhea, urinary incontinence, convulsion, and hypotension. Loss of consciousness was seen in $30.4 \%$ of patients. Ozturk at al reported this ratio to be $25.27 \%$ (12). In our study, tachycardia and bradycardia were seen in $35.4 \%$ and $5 \%$ of the patients, respectively. This result was similar to results of Ozturk et al and Saadeh et al (11). While tachycardia is due to nicotinic effects on adrenal medulla and sympathetic ganglia, bradycardia occurs because of muscarinic effects (12).

Serum glucose changes in OPP are usually clinically significant (12), as hyperglycemia has been reported many times in the literature (9). Here, we observed hyperglycemia in $67.7 \%$ of patients. The increase in serum glucose is believed to be due to the secondary release of catecholamines from the adrenal medulla (9).

Additional laboratory abnormalities include leukocytosis with a left shift (common) (24), impaired liver function tests and increased serum amylase levels $(12,25,26)$. In our study, we saw leukocytosis and increased serum amylase in $68.7 \%$ and $36.1 \%$ of the patients, respectively, and these findings were in accordance with literature $(9,25)$.

We observed increased aspartate aminotransferase levels in $33 \%$ of the patients, which is reported to be very rare (27). This may be due to various organic solvents found in OPCs. High lactate dehydrogenase levels may be associated with oxidative tissue damage induced by OPCs (28), and this level was also high in $29.8 \%$ of our patients.

The diagnosis of acute OPP is based on a history of exposure and a blood test of red cell and plasma choline- sterase (29). Red blood cell cholinesterase is a true cholinesterase, but cannot be easily measured quickly and routinely. Although $\mathrm{sChE}$ is a pseudocholinesterase, it can be measured quickly in emergencies. Clinical manifestations of OPP generally appear after more than $50 \%$ of sChE is inhibited and are very severe when sChE inhibition is $90 \%$ or more (23). We detected in our study that on admission to the ED, $69.6 \%$ of the male patients and $74.1 \%$ of the female patients had depressed sChE levels by $50 \%$ or more.

Current therapy for OPP includes decontamination, reversal of muscarinic symptoms using atropine, regeneration of acetylcholinesterases using oxime compounds such as pralidoxime (2-PAM), and supportive pulmonary care (30). Atropine antagonizes the effect of Ach reversing the excessive parasympathetic stimulation by competing for identical binding sites at muscarinic receptors (29). Treatment guidelines recommend frequent atropine boluses or infusion therapy until pulmonary secretions are minimized, with endotracheal intubation as needed (30). The most common cause of treatment failure is inadequate atropinization (4). Inadequate atropinization may contribute to high rates of both aspiration pneumonia and death (7). Pralidoxime is a biochemical antidote for OPP; its beneficial effects include reactivation of cholinesterase by cleavage of phosphorylated active sites, direct reaction and detoxification of unbounded OPCs, and an endogenous anticholinergic effect (5). This therapy for OPP also applies to the emergency treatment for sarin, a typical drug of chemical weapons of mass destruction (31). In the present study, atropine and pralidoxime treatment was given in the ED to $58.6 \%$ and $43.6 \%$ of the patients, respectively. The rest of the patient treatments were given in the intensive care unit.

The mortality rate from acute OPP varies between 10$20 \%$, and is generally due to respiratory failure (6). The initial respiratory symptoms as described above and RF consistently develop during the period of cholinergic crisis, usually during the first 24 hours after exposure to OPCs (5). The causes of death and mortality rates of the present patients $(9.1 \%)$ were also in accordance with the literature. Because patients above 75 years of age composed $25 \%$ of dead cases in our study, we think that advanced age may be one of the important factors affecting mortality. This may be explained by the decreased physiological reserves in elderly.

In conclusion, it is obvious that OPP is still an important health problem in Turkey as in other countries and it primarily affects the reproductive age group. In these poisonings, suicidal purposes are in the foreground. We think that the appropriate use of these compounds, instruction of the public about their harmful effects and restriction of their uncontrolled sales by legal regulations can reduce OPP incidence.

\section{References}

1. Aygun D. Diagnosis in an acute organophosphate poisoning: report of three interesting cases and review of the literature. Eur J
Emerg Med 11: 55-58, 2004.

2. Bardin PG, van Eeden SF, Moolman JA, Foden AP, Joubert JR. 
Organophosphate and carbamate poisoning. Arch Intern Med 154: 1433-1441, 1994

3. Karalliedde L. Organophosphorus poisoning and anaesthesia. Anaesthesia 54: 1073-1088, 1999.

4. Robey WC, Meggs WJ. Insecticides, Herbides, Rodenticides. In: Emergency Medicine: A Comprehensive Study Guide. Tintinalli JE, Kelen GD, Stopczyski JS, Eds. Mc Graw Hill, New York, 2000: 1174-1176.

5. Tsao TC, Juang YC, Lan RS, Shieh WB, Lee CH. Respiratory failure of acute organophosphate and carbamate poisoning. Chest 98: 631-636, 1990 .

6. Nouira S, Abroug F, Elatrous S, Boujdaria R, Bouchoucha S. Prognostic value of serum cholinesterase in organophosphate poisoning. Chest 106: 1811-1814, 1994.

7. Emerson GM, Gray NM, Jelinek GA, Mountain D, Mead HJ. Organophosphate poisoning in Perth, Western Australia, 1987-1996. J Emerg Med 17: 273-277, 1999.

8. Bertsias GK, Katonis P, Tzanakakis G, Tsatsakis AM. Review of clinical and toxicological features of acute pesticide poisonings in Crete (Greece) during the period 1991-2001. Med Sci Monit 10: 622-627, 2004.

9. Sungur M, Guven M. Intensive care management of organophosphate insecticide poisoning. Crit Care 5: 211-215, 2001.

10. Balali-Mood M, Shariat M. Treatment of organophosphate poisoning. Experience of nerve agents and acute pesticide poisoning on the effects of oximes. J Physiol Paris 92: 375-378, 1998.

11. Saadeh AM, al-Ali MK, Farsakh NA, Ghani MA. Clinical and sociodemographic features of acute carbamate and organophosphate poisoning: a study of 70 adult patients in north Jordan. J Toxicol Clin Toxicol 34: 45-51, 1996.

12. Ozturk MA, Kelestimur F, Kurtoglu S, Guven K, Arslan D. Anticholinesterase poisoning in Turkey-clinical, laboratory and radiologic evaluation of 269 cases. Hum Exp Toxicol 9: 273-279, 1990.

13. Sahin HA, Sahin I, Arabaci F. Sociodemographic factors in organophosphate poisonings; a prospective study. Hum Exp Toxicol 22: 349-353, 2003.

14. Kara IH, Guloglu C, Karabulut A, Orak M. Sociodemographic, clinical, and laboratory features of cases of organic phosphorus intoxication who attended the Emergency Department in the Southeast Anatolian Region of Turkey. Environ Res 88: 82-88, 2002.

15. Agarwal SB. A clinical, biochemical, neurobehavioral, and sociopsychological study of 190 patients admitted to hospital as a result of acute organophosphorus poisoning. Environ Res 62: 6370, 1993

16. Chharba ML, Sepaha GC, Jain SR, Bhagwat RR, Khandekar JD. E.C.G. and necrosy changes in organophosphorus compound (malathion) poisoning. Indian J Med Sci 24: 424-429, 1970.

17. Eddleston M, Szinicz L, Eyer P, Buckley N. Oximes in acute organophosphorus pesticide poisoning: a systematic review of clinical trials. Q J Med 95: 275-283, 2002.

18. Johnson MK, Jacobson D, Meredith TJ, et al. Evaluation of antidotes for poisoning by organophosphorus pesticides. Emerg Med 12: $22-37,2000$.

19. Thiermann H, Szinicz L, Eyer F, et al. Modern strategies in therapy of organophosphate poisoning. Toxicol Lett 107: 233-239, 1999.

20. Amr MM. Pesticide monitoring and its health problems in Egypt, a Third World country. Toxicol Lett 107: 1-13, 1999.

21. Brown SK, Ames RG, Mengle DC. Occupational illness from cholinesterase-inhibiting pesticides among agricultural applicators in California, 1982-1985. Arch Environ Health 44: 34-39, 1989.

22. Cocker J, Mason HJ, Garfitt SJ, Jones K. Biological monitoring of exposure to organophosphate pesticides. Toxicol Lett 134: 97-103, 2002.

23. Yamashita M, Yamashita M, Tanaka J, Ando Y. Human mortality in organophosphate poisoning. Vet Human Toxicol 39: 84-85, 1997.

24. Ellenhorn MJ, Barcebux DG. Pesticides. In: Ellenhorn's Medical Toxicology:Diagnosis and Treatment of Human Poisoning. Ellenhorn MJ, Ed. Lippincott Williams \& Wilkins, Portland, 1996: 1614-1663.

25. Sahin I, Onbası K, Sahin H, Karakaya C, Ustun Y, Noyan T. The prevalence of pancreatitis in organophosphate poisonings. Hum Exp Toxicol 21: 175-177, 2002.

26. Ikizceli I, Yurumez Y, Avsarogullari L, et al. Effect of interleukin10 on pancreatic damage caused by organophosphate poisoning. Regul Toxicol Pharmacol 42: 260-264, 2005.

27. Kamal AA, Elgarhy MT, Maklady F, Mostafa MA, Massound A. Serum choline esterase and liver function among a group of organophosphorus pesticides sprayers in Egypt. J Toxicol Clin Exp 10: 427-435, 1990.

28. Bagchi D, Bagchi M, Hassound EA, Stohs SJ. In vitro and in vivo generation of reactive oxygen species, DNA damage and lactate dehydrogenase leakage by selected pesticides. Toxicology 104: 129-140, 1995.

29. O'Malley M. Clinical evaluation of pesticide exposure and poisonings. Lancet 349: 1161-1166, 1997.

30. Bird SB, Gaspari RJ, Lee WJ, Dickson EW. Diphenhydramine as a protective agent in a rat model of acute, lethal organophosphate poisoning. Acad Emerg Med 9: 1369-1372, 2002.

31. Krivoy A, Layish I, Rotman E, Goldberg A, Yehezkelli Y. OP or not OP: the medical challenge at the chemical terrorism scene. Prehospital Disaster Med 20: 155-158, 2005.

(C) 2007 The Japanese Society of Internal Medicine http://www.naika.or.jp/imindex.html 